\title{
Article \\ Sn Content Effects on Microstructure, Mechanical Properties and Tribological Behavior of Biomedical Ti-Nb-Sn Alloys Fabricated by Powder Metallurgy
}

\author{
Fangxia Xie ${ }^{1,2, *}$, Hao Yang ${ }^{1}$, Jiabing Huang ${ }^{1}$, Jinghu $\mathrm{Yu}^{1,2}$ and Xueming He ${ }^{1,2}$ \\ 1 School of Mechanical Engineering, Jiangnan University, Wuxi 214122, China; yanghao0603@126.com (H.Y.); \\ HUANGJiaBing1996@163.com (J.H.); jhyu@jiangnan.edu.cn (J.Y.); hxueming2003@163.com (X.H.) \\ 2 Key Laboratory of Advanced Food Manufacturing Equipment and Technology, Wuxi 214122, China \\ * Correspondence: xiefangxia@aliyun.com; Tel.: +86-0510-8591-0562
}

check for

updates

Citation: Xie, F.; Yang, H.; Huang, J.; Yu, J.; He, X. Sn Content Effects on Microstructure, Mechanical Properties and Tribological Behavior of Biomedical Ti-Nb-Sn Alloys Fabricated by Powder Metallurgy. Metals 2022, 12, 255. https://doi.org/ $10.3390 /$ met12020255

Academic Editor: Marco A. L. Hernandez-Rodriguez

Received: 31 December 2021

Accepted: 25 January 2022

Published: 29 January 2022

Publisher's Note: MDPI stays neutral with regard to jurisdictional claims in published maps and institutional affiliations.

Copyright: (c) 2022 by the authors. Licensee MDPI, Basel, Switzerland. This article is an open access article distributed under the terms and conditions of the Creative Commons Attribution (CC BY) license (https:// creativecommons.org/licenses/by/ $4.0 /)$.

\begin{abstract}
A group of Ti-10Nb-xSn alloys with Sn content varying from 0 to 8 wt.\% were fabricated from blended elemental powders using powder metallurgy processing. The effects of the Sn content on the microstructure, mechanical performance, and tribological behavior were investigated. The results showed that Ti-10Nb-xSn alloys with high density could be fabricated using powder metallurgy. When the Sn content increased from 0 to $8 \mathrm{wt} . \%$, the density increased slightly from $96.76 \%$ to $98.35 \%$. The alloys exhibited a typical $\alpha+\beta$ microstructure. As the Sn content increased, the dendritic $\beta$ grains gradually converted into a laminar $\alpha+\beta$ structure, accompanied by intergranular $\alpha$ and a small number of micropores. The elastic modulus of the alloys decreased with increasing Sn content but not significantly (73-76 GPa). The addition of Sn initially reduced the Vickers hardness, compressive strength, and maximum strain. When Sn was added up to $5 \mathrm{wt} \%$, these properties tended to increase slowly in the ranges 310-390 HV, 1100-1370 MPa, and 15.44-23.72\%, respectively. With increasing $\mathrm{Sn}$ content, the friction coefficient of the alloys increased from 0.41 to 0.50 . Without $\mathrm{Sn}, \mathrm{Ti}-10 \mathrm{Nb}$ was dominated by abrasive wear. The wear mechanism of Ti-10Nb-3Sn and Ti-10Nb-5Sn changed to adhesive wear together with abrasive wear with increasing Sn content, while Ti-10Nb-8Sn predominately exhibited adhesive wear. Compared with Ti-10Nb alloy, an appropriate amount of Sn could achieve a lower elastic modulus, while Vickers hardness and compressive strengths were little changed. Moreover, it had a minor influence on the friction coefficient. The good mechanical performance and wear resistance make the powder-metallurgy-fabricated Ti- $10 \mathrm{Nb}-\mathrm{xSn}$ alloys attractive candidates for biomedical materials.
\end{abstract}

Keywords: Ti-10Nb-xSn alloys; microstructure; mechanical properties; wear resistance; powder metallurgy

\section{Introduction}

Titanium alloys are widely used as biomedical implant materials owing to their high specific strength, good corrosion resistance, and excellent biocompatibility [1]. Currently, pure $\mathrm{Ti}$ ( $\alpha$ type) and Ti-6Al-4V ( $\alpha+\beta$ type) are the most commonly used biomaterials. However, the elastic modulus of the two alloys are considerably higher than that of human bone. This can lead to a stress shielding phenomenon after implantation [2]. In addition, the release of $\mathrm{Al}$ and $\mathrm{V}$ ions has been proven to be toxic to humans and may cause Alzheimer's disease [3,4]. To solve these problems, it is necessary to develop a new biomedical titanium alloy with low elastic modulus and good biocompatibility.

At present, biomedical titanium alloys are developed by adding non-toxic, noninflammatory, and non-allergic elements to pure $\mathrm{Ti}$, such as $\mathrm{Nb}, \mathrm{Zr}, \mathrm{Mo}, \mathrm{Sn}$, and $\mathrm{Ta}$. A series of new titanium alloys have been developed, including Ti- $13 \mathrm{Nb}-13 \mathrm{Zr}$, Ti- $5 \mathrm{Mo}-3 \mathrm{Nb}$, and Ti-29Nb-13Ta-5Zr [5]. They not only have a lower elastic modulus, higher strength, and better corrosion resistance but also good biocompatibility. However, because of the addition of high-melting-point elements (such as $\mathrm{Nb}, \mathrm{Zr}$ and $\mathrm{Ta}$ ), they are more difficult to 
manufacture [6]. When titanium alloys are manufactured by traditional fusion casting, it is easy to cause component segregation, leading to inhomogeneous properties. Powder metallurgy (PM) can be used to fabricate refractory metals at a low cost and in a short production cycle. In addition, it can better control the alloy composition.

Ti-Nb-Sn alloys have attracted substantial attention in recent years [7-9]. Some studies have been conducted on their mechanical properties. It has been proven that the addition of $\mathrm{Nb}$ can improve the microstructure and reduce the elastic modulus of alloys [10]. Moreover, the superelasticity and corrosion behavior are also important for biomedical materials. The addition of Sn has significant effects on elastic recovery and the composition of the surface oxide film [11]. It has been found that Ti-Nb-Sn alloys can maintain excellent superelasticity and good corrosion resistance [12].

In this study, Ti-10Nb-xSn $(x=0,3,5$, and $8 \mathrm{wt} . \%)$ alloys were fabricated using PM. The effects of the Sn content on the microstructure and mechanical properties of Ti- $10 \mathrm{Nb}-\mathrm{xSn}$ alloys were investigated. As metal implant materials, the wear resistance of the alloys must be considered to avoid the generation of grinding debris during movement. Otherwise, too much grinding debris will be released into human tissues. This would result in loosening and eventually reduce the service life of the implant [13]. Therefore, the tribological behavior of the alloys was also studied using the friction and wear tests.

\section{Experimental Procedure}

\subsection{Preparation of Specimens}

$\mathrm{Ti}, \mathrm{Nb}$, and $\mathrm{Sn}$ powders with a purity of $99.9 \%$ were used as raw materials. Powder mixtures with a nominal composition of Ti- $10 \mathrm{Nb}-\mathrm{xSn}(\mathrm{x}=0,3,5$, and $8 \mathrm{wt} . \%)$ were milled using a ball milling machine (Nanjing NanDa Instrument Plant, QM-3SP4, Nanjing, China) for $10 \mathrm{~h}$. The grinding ball was made of 304 stainless steel. The frequency of vibration of the ball-milling machine and the ball-to-powder weight ratio were $300 \mathrm{r} / \mathrm{min}$ and 3:1, respectively. To prevent the powder from sticking to the mill pot, $2 \mathrm{wt} . \%$ stearic acid was added. Cylindrical specimens $20 \mathrm{~mm}$ in diameter and $10 \mathrm{~mm}$ in height were obtained by pressing the milled powder under $600 \mathrm{MPa}$ at room temperature. The cylindrical compacts were sintered in a tube furnace (Hefei Kejing Material Technology Inc., GSL-1700x, Hefei, China) with high-purity argon gas protection. The resultant specimens were sintered at $1300{ }^{\circ} \mathrm{C}$ for $2 \mathrm{~h}$. After that, the specimens were cooled to room temperature in the furnace. The density was measured using Archimedes' drainage method. The specific formula is as follows:

$$
d=\rho / \rho_{0} \times 100 \%
$$

where $d$ is the relative density of the alloy, $\rho$ is the destiny measured using Archimedes principle, $\rho_{0}$ is the theoretical density of the alloy estimated using the following equation:

$$
\rho_{0}=1 /\left(\left((\mathrm{A} \%) / \rho_{\mathrm{A}}\right)+\left((\mathrm{B} \%) / \rho_{\mathrm{B}}\right)+\left((\mathrm{C} \%) / \rho_{\mathrm{C}}\right)\right)
$$

where $\mathrm{A} \%, \mathrm{~B} \%$, and $\mathrm{C} \%$ are the weight fractions of the constituent alloying elements, and $\rho_{\mathrm{A}}, \rho_{\mathrm{B}}$, and $\rho_{\mathrm{C}}$ are their respective theoretical densities $\left(\rho_{\mathrm{A}}=4.506 \mathrm{~g} / \mathrm{cm}^{3}, \rho_{\mathrm{B}}=8.57 \mathrm{~g} / \mathrm{cm}^{3}\right.$ and $\left.\rho_{C}=7.298 \mathrm{~g} / \mathrm{cm}^{3}\right)$. The density measurements were repeated three times for each alloy.

For microstructural studies, specimens were prepared using standard metallographic procedures. The phases present in the sintered alloys were identified using X-ray diffraction (XRD) with a X-ray diffractometer (Bruker Co., D8 Advance, Karlsruhe, Germany) equipped with an energy dispersive X-ray spectrometer (EDS). The microstructure of the specimens was characterized using scanning electron microscopy (SEM) with a scanning electron microscope (ZEISS Co., Sigma HD, Oberkochen, Germany).

\subsection{Mechanical Tests}

To determine the mechanical properties, compression and hardness tests were performed at room temperature. Cylindrical specimens $6 \mathrm{~mm}$ in diameter and $10 \mathrm{~mm}$ in height were prepared from the sintered alloys. Compression tests were conducted using a 
universal testing machine (Jinan Sida Test Technology Inc., WDW-100, Jinan, China) at a loading rate of $0.2 \mathrm{~mm} / \mathrm{min}$. The elastic modulus, yield strength, and compressive strength were measured in triplicate for each alloy composition, and the average value was taken. The fracture surfaces were observed using SEM. Vickers hardness measurements on the polished samples were performed using a Vickers hardness tester (Shanghai Suoyan Testing Instrument Inc., JVS-1000ZCM-XY, Shanghai, China)with a load and dwell time of $4.9 \mathrm{~N}$ and $10 \mathrm{~s}$, respectively. The reported Vickers hardness values represent the average of at least five measurements.

\subsection{Tribological Tests}

The tribological tests were developed using a friction and wear tester (Rudolph Technologies Inc., MFT-5000, New Jersey, America). Specimens were cut to $20 \mathrm{~mm}$ in diameter and $8 \mathrm{~mm}$ in height. All tests were conducted at room temperature with a load of $10 \mathrm{~N}$ for $30 \mathrm{~min}$. The slip frequency was $1 \mathrm{~Hz}$, and the stroke length was $5 \mathrm{~mm}$. The grinding material was a $40 \mathrm{Cr}$ stainless-steel ball with a diameter of $10 \mathrm{~mm}$. The coefficient of friction was used to characterize the wear resistance and the worn surfaces were analyzed using SEM and EDS.

\section{Results and Discussion}

\subsection{Microstructure}

Table 1 shows the relative density of the Ti-10Nb-xSn alloys fabricated by PM. The relative density of the Ti- $10 \mathrm{Nb}-x \mathrm{Sn}$ alloys increased slightly with the addition of Sn. Sn has been confirmed to reduce the sintering temperature of the solid and liquid phases of titanium alloys, and thus increases the driving force for the sintering processing [14,15]. The alloying elements diffuse in the Ti matrix at different rates, and the diffusion rate of $\mathrm{Sn}$ is considerably higher than that of $\mathrm{Nb}$. Thus, Sn could improve the sintering reaction and increase the density.

Table 1. Relative destiny of PM-fabricated Ti-10Nb-xSn alloys.

\begin{tabular}{ccccc}
\hline Specimens & Ti-10Nb & Ti-10Nb-3Sn & Ti-10Nb-5Sn & Ti-10Nb-8Sn \\
\hline Relative destiny & $96.76 \pm 0.17$ & $97.18 \pm 0.19$ & $97.89 \pm 0.14$ & $98.35 \pm 0.16$ \\
\hline
\end{tabular}

Figure 1 displays XRD patterns of the Ti-10Nb-xSn alloys. According to the XRD results, the Ti-10Nb-xSn alloys were composed of $\alpha$ and $\beta$ phases. The strongest diffraction peak of the Ti-10Nb alloy was for the $\alpha$ phase (Figure 1a). With the addition of $\mathrm{Sn}$, the diffraction intensity of major peaks for $\alpha$ phase became weaker gradually (Figure $1 b-d)$. This indicated that the addition of $\mathrm{Sn}$ allowed more $\beta$ phase to be retained during cooling. In addition, no noticeable diffraction peaks from $\mathrm{Nb}$ and $\mathrm{Sn}$ were detected in the XRD patterns. This indicated that the two alloying elements fully diffused into the titanium matrix during the sintering process.

Figure 2 shows the microstructures of the Ti- $10 \mathrm{Nb}-\mathrm{xSn}$ alloys. It can be seen that the alloys had typical $\alpha+\beta$ microstructures. Some tiny holes were also observed, which were caused by the decomposition and removal of stearic acid during sintering. The PMfabricated Ti-10Nb-xSn alloys were cooled in a furnace to room temperature, and the $\beta$ phase was partially preserved. In addition, no residual $\mathrm{Nb}$ and $\mathrm{Sn}$ particles were detected. This is consistent with the XRD results. As shown by the arrows in Figure $2 \mathrm{a}$, the Ti- $10 \mathrm{Nb}$ alloy was mainly composed of large irregularly shaped $\alpha$ (dark-gray region) and branched $\beta$ (bright-gray region) grains. When $S n$ was added (Figure $2 b$ ), the size and scale of the $\alpha$ phase decreased. The dendritic $\beta$ phase grew in size and increased in proportion. The $\beta$ phase retained more, and the $\alpha / \beta$ phase ratio decreased with further increases in Sn content. In addition, the $\alpha+\beta$ lamellae and intragranular $\alpha$ were observed (Figure 2c). When the Sn content reached $8 \mathrm{wt} \%$, more of the $\beta$ phase was retained, and the ratio 
and size of the $\alpha$ phase were further reduced. Additionally, the $\alpha+\beta$ lamellar structure increased in size, together with the intragranular $\alpha$, as shown in Figure $2 \mathrm{~d}$.

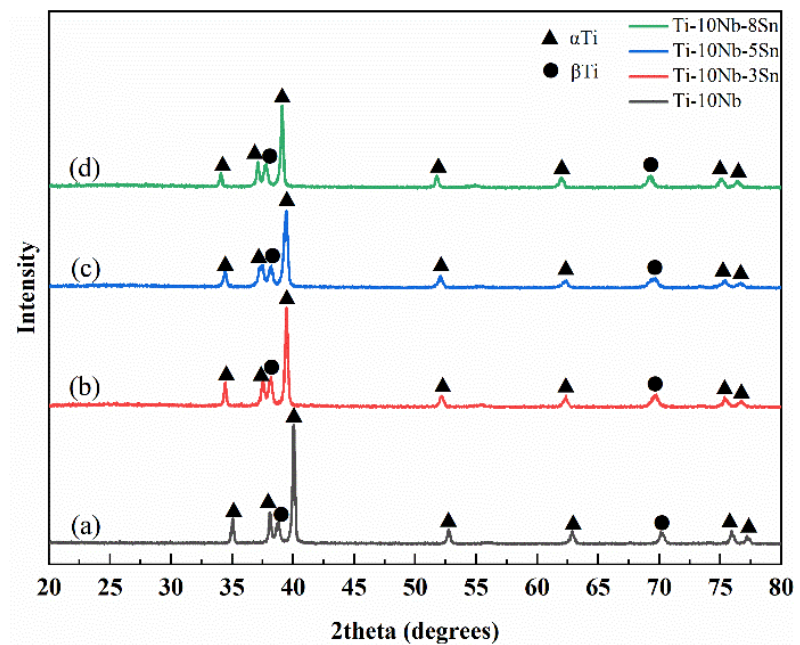

Figure 1. XRD patterns of PM-fabricated Ti-10N-xSn alloys: (a) Ti-10Nb, (b) Ti-10Nb-3Sn, (c) Ti-10Nb$5 \mathrm{Sn}$, and (d) Ti-10Nb-8Sn.
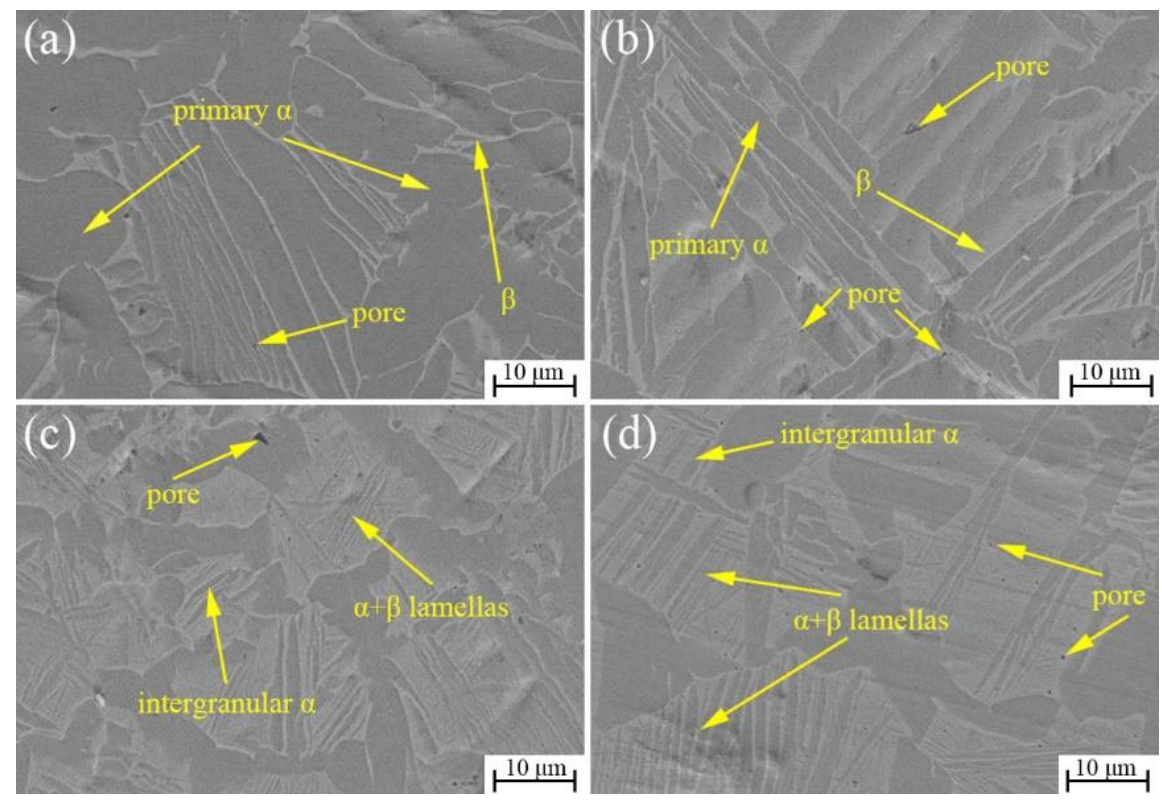

Figure 2. Microstructural images of PM-fabricated Ti-10Nb-xSn alloys: (a) Ti-10Nb, (b) Ti-10Nb-3Sn, (c) Ti-10Nb-5Sn, and (d) Ti-10Nb-8Sn.

Sn was generally considered to be a neutral element with no significant effect on the stability of the $\alpha$ and $\beta$ phases but forming solid solutions with titanium [16,17]. Based on the above results, this study concluded that the addition of $S n$ was beneficial to improve the stability of $\beta$ phase and prevent the conversion of $\beta$ to $\alpha$ during furnace cooling to some extent. Some studies suggested that $S n$ could effectively reduce the initial martensitic transformation temperature and stabilize the $\beta$ phase $[18,19]$. From the XRD patterns, it was found that the diffraction intensity of the $\alpha$-phase peak became weaker, and the $\beta$ phase was better retained with the addition of Sn $[20,21]$. Sn was also proven to prevent the formation of $\alpha$-phase nuclei, thus preserving more $\beta$ phase [22].

Figure 3 shows the elemental distributions of $\mathrm{Ti}, \mathrm{Nb}$ and $\mathrm{Sn}$ in the Ti-10Nb-8Sn alloy obtained from energy-dispersive spectroscopy measurements. Ti was mainly distributed in the dark-gray regions ( $\alpha$ phase) (Figure $3 b$ ), while $\mathrm{Nb}$ and $\mathrm{Sn}$ were mainly distributed in 
the light-gray regions ( $\beta$ phase) (Figure $3 \mathrm{c}, \mathrm{d}$ ). This observation also confirmed that $\mathrm{Nb}$ and Sn acted as $\beta$ stabilizers, which resulted in their increased distribution in the $\beta$ matrix.
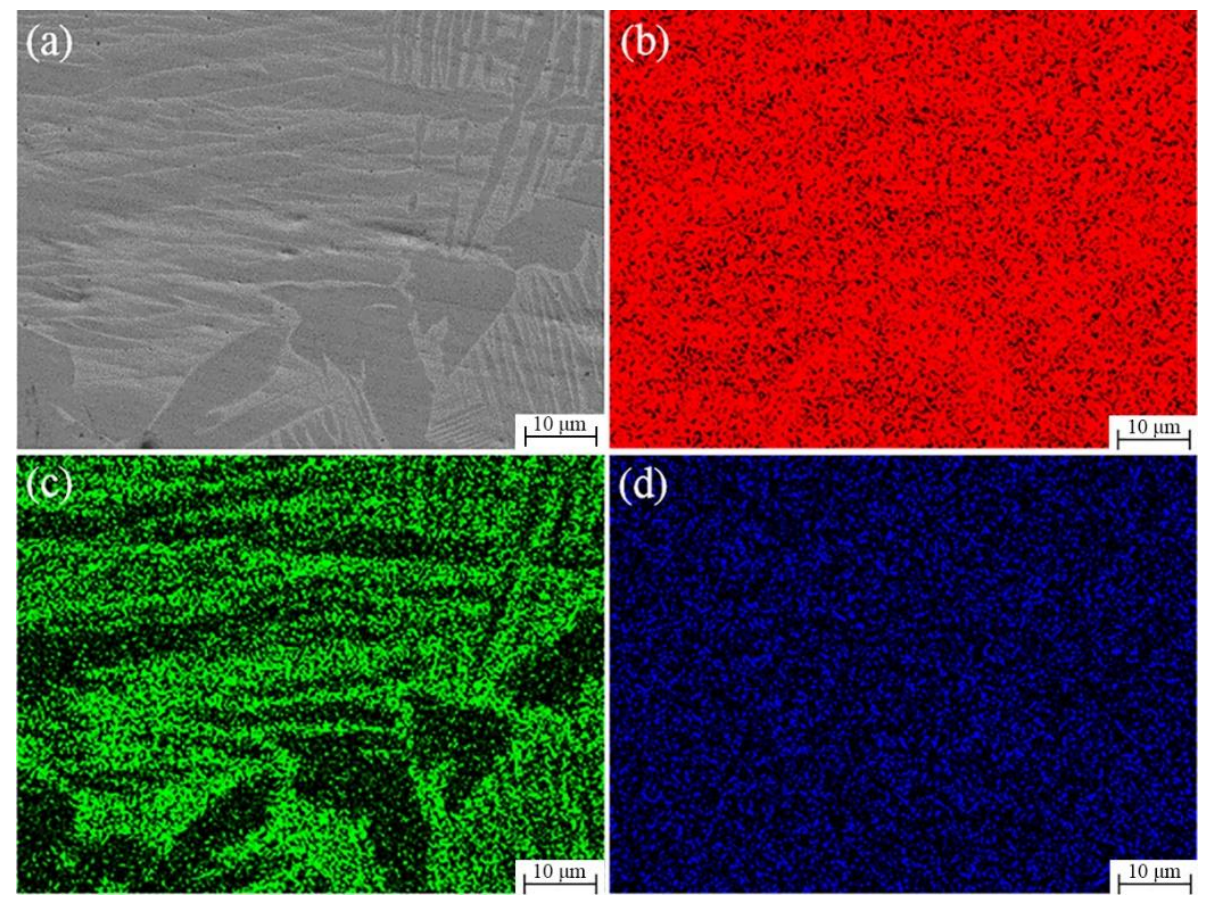

Figure 3. Elemental distribution in PM-fabricated Ti-10Nb-8Sn alloy: (a) SEM image, and elemental maps of (b) Ti, (c) Nb, and (d) Sn.

\subsection{Mechanical Properties}

Figures 4 and 5 show the effects of Sn content on the Vickers hardness and compression properties of the Ti-10Nb-xSn alloys, respectively. The results showed that when Sn was added to the Ti-10Nb alloy, the hardness tended to decrease. The Vickers hardness of Ti$10 \mathrm{Nb}$ was $388.7 \mathrm{HV}$, while that of Ti-10Nb-3Sn decreased to $310 \mathrm{HV}$. However, the hardness gradually increased with further $\mathrm{Sn}$ addition, and that of Ti-10Nb-8Sn rose to $389.7 \mathrm{HV}$. The elastic modulus of the Ti-10Nb-xSn alloys declined slightly from 76 to $73 \mathrm{GPa}$ as the $\mathrm{Sn}$ content increased from 0 to $8 \mathrm{wt} . \%$.

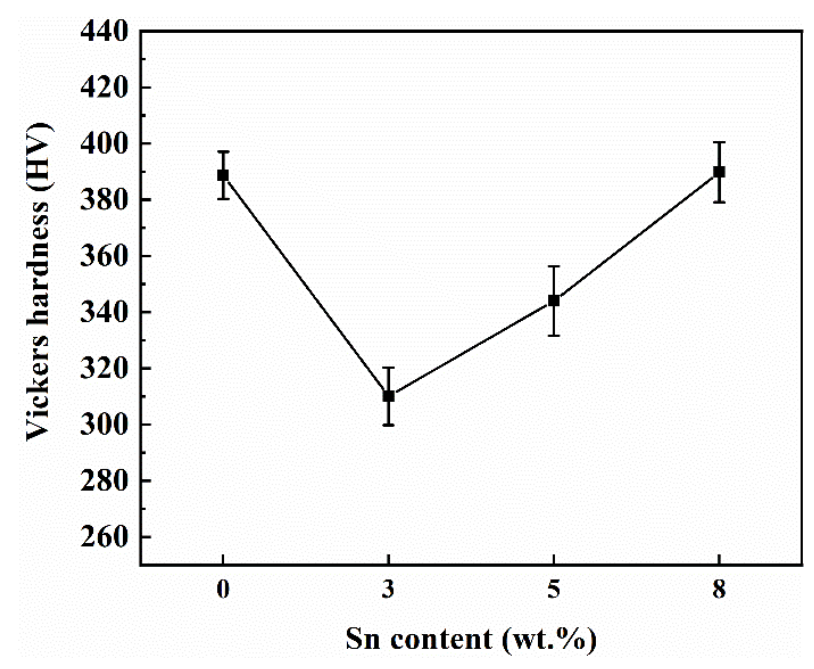

Figure 4. Vickers hardness of PM-fabricated Ti-10Nb-xSn alloys. 


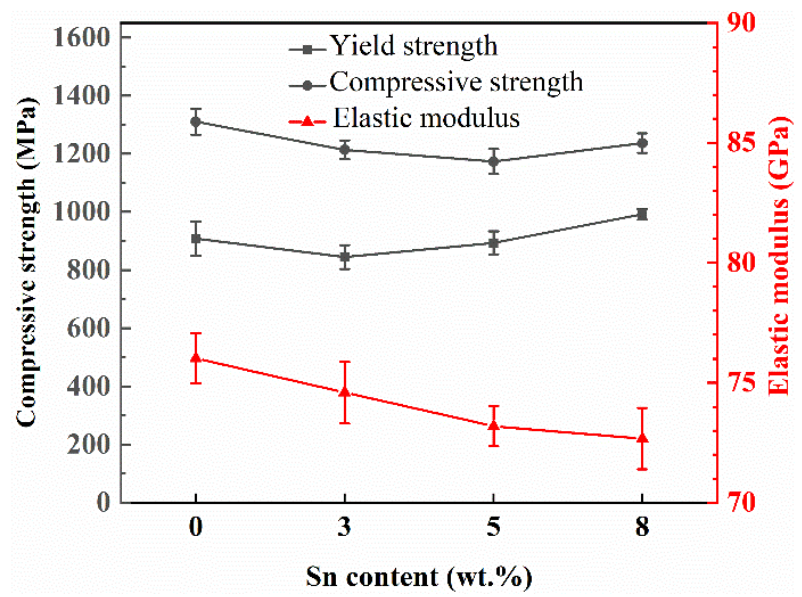

Figure 5. Compressive strengths and elastic modulus of PM-fabricated Ti-10Nb-xSn alloys.

It is well known that the mechanical properties of titanium alloys are related to the morphology and fractions of phases in the microstructure. With $\mathrm{Sn}$ addition, the proportion of $\alpha$ phase decreased. The hardness and elastic modulus of the $\alpha$ phase are higher than those of the $\beta$ phase. It was one reason why the hardness and elastic modulus went down. It may also be attributed to the inhibition of Sn addition on the formation of the $\omega$ phase [23]. This would reduce the $\omega$ phase fraction in the alloy, which would then reduce the hardness and elastic modulus of the alloys [24]. However, the $\omega$ phase is difficult to detect on XRD. The decrease in hardness and elastic modulus could also be ascribed to the increase in the lattice parameters of the $\beta$ phase. Moraes and Buckley et al. $[25,26]$ noted that the addition of $S n$ causes the $\beta$ crystal lattice to expand. Crystal lattice expansion increased the interatomic distance and thus weakened the bonding force among atoms. As a result, the hardness and elastic modulus were reduced. When the content of Sn was increased further, the diffusion of $\mathrm{Sn}$ into Ti and $\mathrm{Nb}$ generated solid- solution strengthening $[27,28]$, resulting in increased hardness.

Figure 6 shows the stress-strain curves of Ti-10Nb-xSn alloys and SEM images of the fracture surfaces. With increasing Sn content, the yield strength and compressive strength tended to first decrease and then increase. The yield strength and compressive strength of the Ti-10Nb alloy were $963 \mathrm{MPa}$ and $1362 \mathrm{MPa}$, respectively. With the addition of $5 \mathrm{wt}$ \% Sn, the yield strength and compressive strength of the alloy decreased to $895 \mathrm{MPa}$ and $1144 \mathrm{MPa}$, respectively. When the Sn content increased further to $8 \mathrm{wt} \%$, the yield strength and compressive strength of the alloy rose to $1011 \mathrm{MPa}$ and $1270 \mathrm{MPa}$, respectively (Figure 6a). The maximum strain also showed the same trend. The maximum strain of $\mathrm{Ti}-10 \mathrm{Nb}$ was $23.72 \%$, and it decreased after the addition of $\mathrm{Sn}(21.69 \%$ and $15.44 \%$ for Ti-10Nb-3Sn and Ti-10Nb-5Sn, respectively). When the Sn content reached $8 \mathrm{wt} . \%$, the maximum strain slightly increased to $17.24 \%$. Sn prevents the transformation of $\beta$ to $\alpha$. The $\alpha$ phase possesses a hexagonal close-packed structure, while the $\beta$ phase is a bodycentered cubic crystal. The body-centered cubic structure has more slip systems than the hexagon close-packed structure; therefore, it has more resistance to dislocation motion, thus increasing the strength. Additionally, a small amount of intragranular $\alpha$ phase that precipitated from the $\beta$ phase also contributed to the increased strength of the alloys [29], which is why the strengths of Ti-10Nb-5Sn and Ti-10Nb-8Sn were higher than that of Ti$10 \mathrm{Nb}-3 \mathrm{Sn}$. The elastic modulus of human cortical bone is $10-30 \mathrm{GPa}$, and the compressive strength is $90-140 \mathrm{MPa}$ [30]. The present Ti-10Nb-xSn alloys can meet the mechanical requirements of hard tissue replacement materials.

Interparticle interfaces from the powder could not be distinguished on the fracture surface, which indicates that the titanium alloys achieved complete sintering. After the compression test, the angle between the fracture surface of the alloys and the loaded-force was $45^{\circ}$. This implies that shear failure occurred after compression of the Ti-10Nb-xSn alloys [31,32]. As shown in Figure 6b, the surface of the Ti-10Nb alloy was fibrous with a 
herringbone ridge pattern, which are the main characteristics of ductile fracture. When 8 wt. $\%$ Sn was added, the rough region of the fracture surface covered a greater area than that of the smooth one (Figure 6c), indicating that the fracture mechanism of the Ti-10Nb-8Sn alloy was mainly ductile fracture along with a brittle feature. In addition, some microcracks could be observed, which may have been caused by micropores in the microstructures [33].
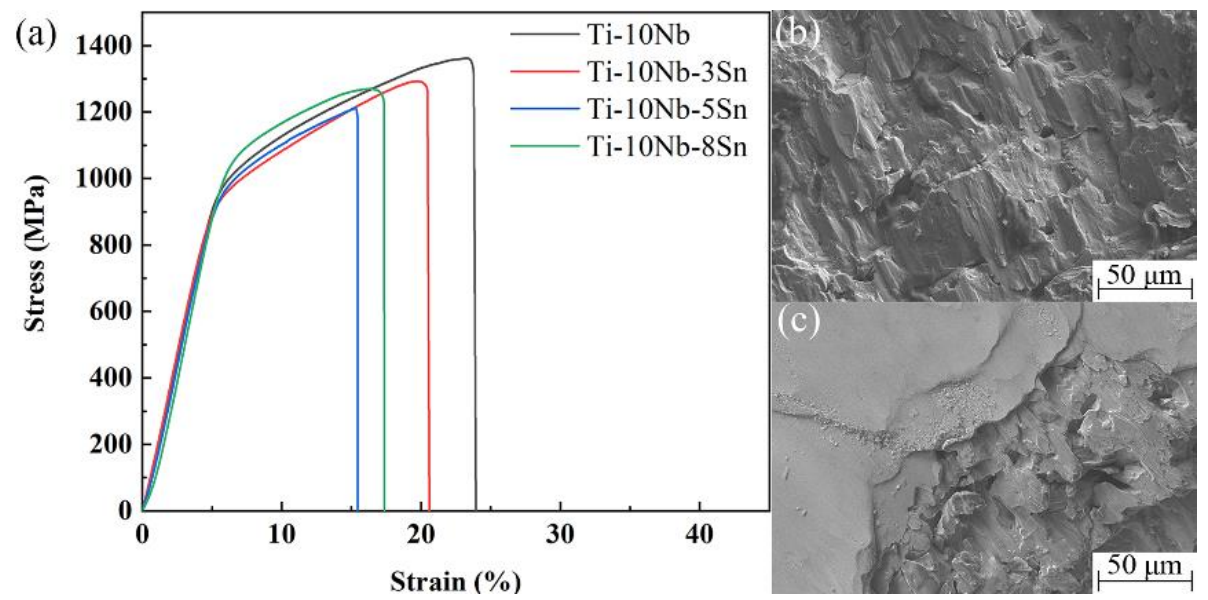

Figure 6. Compressive stress-strain curves of PM-fabricated Ti-10Nb-xSn alloys (a), and SEM images of fracture surface: (b) Ti-10Nb, (c) Ti-10Nb-8Sn.

\subsection{Tribological Behavior}

Figure 7 presents curves of the friction coefficient of the Ti-10Nb-xSn alloys. It can be seen that the friction coefficient increased considerably in the first $10 \mathrm{~min}$. After that, the friction coefficient was generally stable, and the fluctuation amplitude decreased. Through calculation, the friction coefficients of $\mathrm{Ti}-10 \mathrm{Nb}$ and $\mathrm{Ti}-10 \mathrm{Nb}-3 \mathrm{Sn}$ were approximately 0.41 , while those of Ti-10Nb-5Sn and Ti-10Nb-8Sn were 0.45 and 0.50 , respectively. Clearly, the increase in $\mathrm{Sn}$ content led to an increase in the friction coefficient of the Ti-10Nb-xSn alloys.

The wear resistance of titanium alloys is related to the surface oxide and hardness. $\mathrm{Nb}_{2} \mathrm{O}_{5}$ oxide films form on the surface of titanium alloys containing $\mathrm{Nb}$, which has good lubricity and improves wear resistance [34]. In addition, an increase in hardness could also improve the wear resistance of titanium alloys [35]. The Ti-10Nb alloy had a higher hardness; thus, it had a smaller friction coefficient and better wear resistance. Based on a study of the friction and wear behavior of Al-Sn-Si alloys, Bertelli et al. [36] found that increasing the Sn content resulted in a coarser microstructure and wider dendrite arm spacing. This resulted in deeper grinding cracks and increased the abrasion loss, leading to decreased wear resistance. Although $\mathrm{Sn}$ is a self-lubricating element, excessive addition of Sn will cause the lamellae in Ti-10Nb-xSn alloys to grow, which is not conducive to wear resistance. This may be the reason for the reduced wear resistance of the Ti-10Nb-5Sn and Ti-10Nb-8Sn alloys.

Figure 8 depicts the surface morphology of the grinding cracks in the Ti- $10 \mathrm{Nb}-\mathrm{xSn}$ alloys. Furrows with different depths and various degrees of plastic deformation could be observed on the wear surfaces due to the extrusion and friction of the grinding ball. As shown in Figure $8 \mathrm{a}, \mathrm{Ti}-10 \mathrm{Nb}$ had several abrasive particles and little plastic deformation on the wear surface, indicating that abrasive wear had occurred. Some of the grinding debris stuck to the surface of the grinding ball and simultaneously was repeatedly extruded during the friction process. Then, the grinding debris fell off after hardening and fatigue. Therefore, the abrasive particles were generated on the friction contact surface, forming abrasive wear. As Sn was added to the Ti-10Nb alloy, the number of abrasive particles gradually decreased, as shown in Figure 8b,c. Furthermore, Ti-10Nb-8Sn (Figure 8d) had almost no abrasive particles and heavy plastic deformation on the wear surface, indicating that mainly adhesive wear occurred. Because of the pressure and shear force of the grinding 
ball, the plastic deformation appeared on the alloy surface. The alloy surface broke with the accumulation of plastic deformation [37]. This suggests that adhesive wear was the main wear mechanism. In conclusion, the abrasive wear primarily occurred on the wear surface of Ti- $10 \mathrm{Nb}$ and Ti-10Nb-3Sn. The wear mechanism of Ti- $10 \mathrm{Nb}-5 \mathrm{Sn}$ changed to adhesive wear along with abrasive wear, while that of Ti-10Nb-8Sn was dominated by adhesive wear.
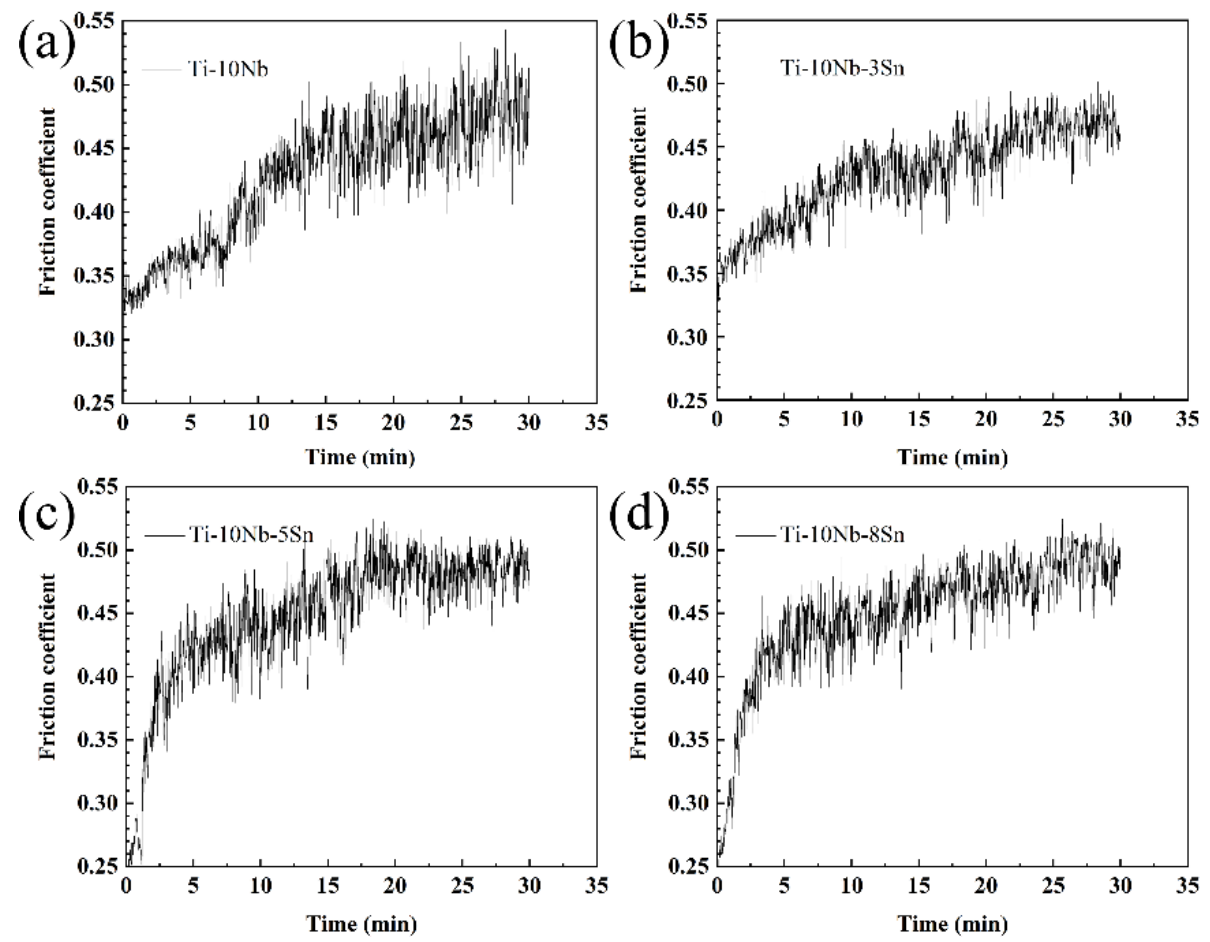

Figure 7. Friction coefficient curves of PM-fabricated Ti-10Nb-xSn alloys: (a) Ti-10Nb, (b) Ti-10Nb-3Sn, (c) Ti-10Nb-5Sn, (d) Ti-10Nb-8Sn.
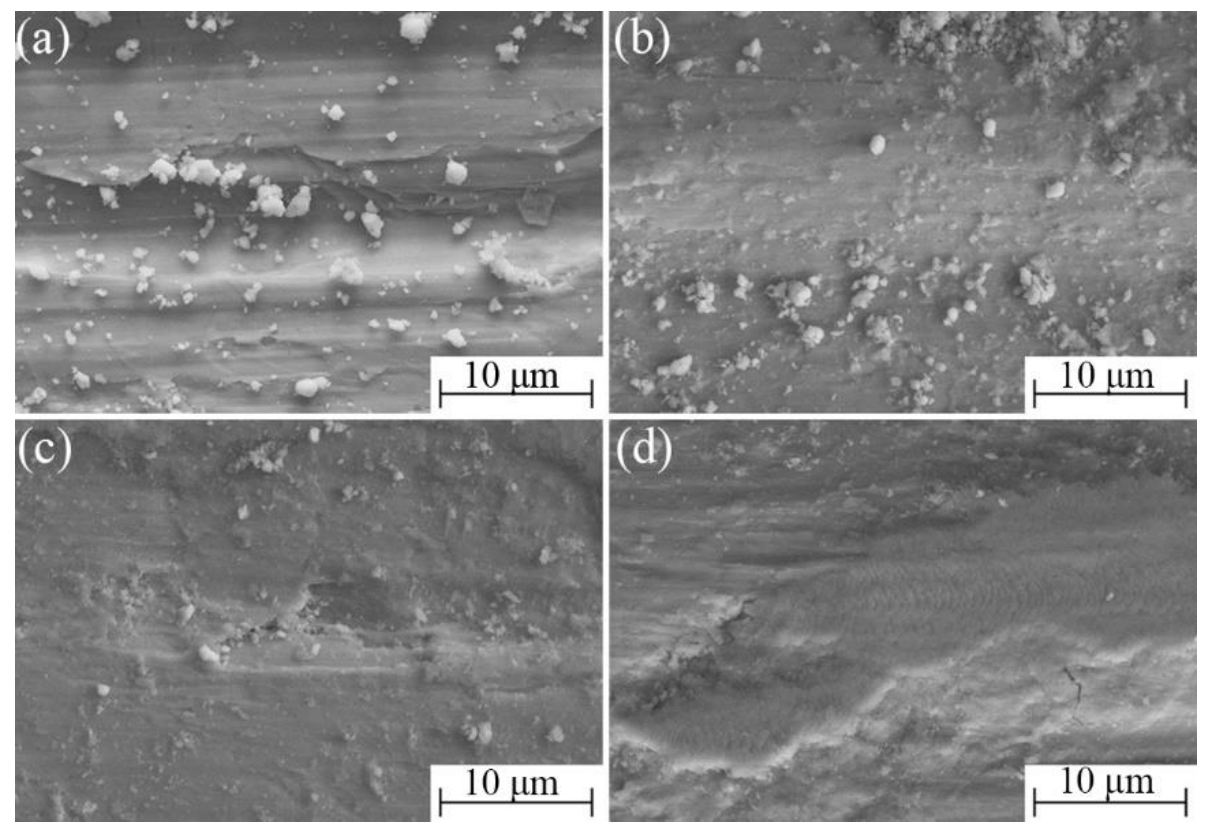

Figure 8. Surface morphology of the grinding cracks of PM-fabricated Ti-10Nb-xSn alloys: (a) Ti-10Nb, (b) Ti-10Nb-3Sn, (c) Ti-10Nb-5Sn, (d) Ti-10Nb-8Sn. 


\subsection{Potential Applications}

In order to serve for a long period in the human body without rejection, an implant material should possess suitable mechanical properties (i.e., low modulus and high strength), good biocompatibility, high corrosion resistance and wear resistance, and osseointegration [1]. According to previous reports, $\mathrm{Sn}$ is a kind of non-toxic, non-inflammatory, and non-allergic element [38,39]. As one of the neutral alloying elements ( $\mathrm{Sn}$ and $\mathrm{Zr}$ ) of $\mathrm{Ti}$, $\mathrm{Sn}$ is usually used in the preparation of biomedical Ti alloys. In this study, the elastic modulus of the Ti-Nb-Sn alloy slightly decreased with increasing Sn content (73-76 GPa), and the compressive strength first decreased and then increased (1100-1370 MPa). Compared with the traditional Ti-6Al-4V (elastic modulus $110 \mathrm{GPa}$, compressive strength $1200 \mathrm{MPa}$ ), the $\mathrm{Ti}-\mathrm{Nb}-\mathrm{Sn}$ alloy presented better mechanical compatibility. However, more Sn addition (8 wt.\%) can lead to adhesive wear, which will reduce wear resistance. The prosthesis at the movable joint has a higher requirement for wear resistance. Considering the mechanical properties and wear resistance, $\mathrm{Ti}-10 \mathrm{Nb}-5 \mathrm{Sn}$ is superior to the other Ti-Nb-Sn alloy for orthopedic implants, such as spinal, shoulder, knee and hip replacements.

\section{Conclusions}

Ti-10Nb-xSn alloys with different $\mathrm{Sn}$ content were prepared from mixed element powders by a compacting and sintering process. Based on the study of the microstructural, mechanical and tribological performances of the alloys, the following conclusions were drawn:

1. Ti-10Nb-xSn alloys had a two-phase $\alpha+\beta$ structure. With the addition of Sn, the $\alpha$ phase became finer and its relative proportion decreased, while the $\beta$ phase grew in size and increased in proportion. When $5 \mathrm{wt} . \%$ Sn was added, $\alpha+\beta$ lamellae and intragranular $\alpha$ appeared.

2. The Vickers hardness decreased with the addition of Sn. This was ascribed to the inhibition of the $\omega$ phase generation and increase in the crystal lattice expansion. However, increasing the Sn content increased the hardness because of solid-solution strengthening.

3. The addition of $\mathrm{Sn}$ first reduced the elastic modulus and compressive strength of the $\mathrm{Ti}-10 \mathrm{Nb}-\mathrm{xSn}$ alloys, while the compression properties started to increase once the $\mathrm{Sn}$ content reached $5 \mathrm{wt} . \%$. Ti- $10 \mathrm{Nb}$ possessed the feature of ductile fracture, while the Ti- $10 \mathrm{Nb}-\mathrm{xSn}(\mathrm{x}=3,5$, and $8 \mathrm{wt} . \%)$ alloys mainly exhibited characteristics of ductile fracture along with brittle behavior.

4. The friction coefficient of the Ti- $10 \mathrm{Nb}-\mathrm{xSn}$ alloys increased slightly as the Sn content increased. Ti-10Nb and Ti-10Nb-3Sn exhibited the typical characteristics of abrasive wear. With further Sn addition, the wear mechanism of Ti-10Nb-5Sn converted to abrasive wear accompanied by adhesive wear. Finally, adhesive wear mainly occurred on the wear surface of Ti-10Nb-8Sn.

5. Combined the mechanical compatibility with wear resistance, $\mathrm{Ti}-10 \mathrm{Nb}-5 \mathrm{Sn}$ maybe more suitable to orthopedic implant material than the other Ti-Nb-Sn alloy.

Author Contributions: Research design F.X. and X.H.; testing H.Y. and J.H.; data analysis H.Y. and J.H.; literature research F.X. and J.Y.; manuscript writing H.Y., J.H. and F.X. All authors have read and agreed to the published version of the manuscript.

Funding: This work was financially supported by the National Natural Science Foundation of China (51501073), Jiangsu Provincial Natural Science Foundation of China (BK20140162), and the Fundamental Research Funds for the Central Universities (JUSRP11455).

Data Availability Statement: The raw/processed data required to reproduce these findings cannot be shared at this time as the data also forms part of an ongoing study.

Conflicts of Interest: The authors declare no conflict of interest. 


\section{References}

1. Geetha, M.; Singh, A.K.; Asokamani, R.; Gogia, A.K. Ti based biomaterials, the ultimate choice for orthopedic implants-A review. Prog. Mater. Sci. 2009, 54, 397-425. [CrossRef]

2. Niinomi, M. Recent research and development in titanium alloys for biomedical applications and healthcare goods. Sci. Technol. Adv. Mater. 2003, 4, 445-454. [CrossRef]

3. Li, Z.J.; Dong, A.P.; Xing, H.; Wang, Y.S. Microstructure and mechanical properties of bimodal Ti-Bi alloys fabricated by mechanical alloying and spark plasma sintering for biomedical applications. Mater. Charact. 2020, 161, 110134. [CrossRef]

4. Guo, S.B.; Chu, A.M.; Wu, H.J.; Cai, C.B.; Qu, X.H. Effect of sintering processing on microstructure, mechanical properties and corrosion resistance of Ti-24Nb-4Zr-7.9Sn alloy for biomedical applications. J. Alloys Compd. 2014, 597, 211-216. [CrossRef]

5. Wang, Y.F.; He, L.; Guo, W. Research and application of medical titanium alloy. Titan. Ind. Prog. 2015, 32, 1-6.

6. Zhang, Y.T.; Liu, H.Y.; Wang, C.; Chen, J.; Shi, J.; Wang, L.; Yu, Z.T. Development trend and research application Situation of Biomedical Metal Materials. Hot Work. Technol. 2017, 46, 21-26.

7. Kaur, M.; Singh, K. Review on titanium and titanium-based alloys as biomaterials for orthopaedic applications. Mater. Sci. Eng. C 2019, 102, 844-862. [CrossRef] [PubMed]

8. Li, P.Y.; Ma, X.D.; Tong, T.; Wang, Y.S. Microstructural and mechanical properties of $\beta$-type Ti-Mo-Nb biomedical alloys with low elastic modulus. J. Alloys Compd. 2020, 815, 152412. [CrossRef]

9. Li, L.; Rehman, I.U.; Lim, J.H.; Lee, W.T.; Seol, J.B.; Kim, J.G.; Nam, T.H. Effect of Sn content on microstructure, texture evolution, transformation behavior and superelastic properties of Ti-20Zr-9Nb-(2-5)Sn (at.\%) shape memory alloys. Mater. Sci. Eng. A 2021, 827, 141994. [CrossRef]

10. Banerjee, R.; Nag, S.; Stechschulte, J.; Fraser, H.L. Strengthening mechanisms in Ti-Nb-Zr-Ta and Ti-Mo-Zr-Fe orthopaedic alloys. Biomaterials 2004, 25, 3413-3419. [CrossRef]

11. Zhang, D.C.; Yang, S.; Wei, M.; Mao, Y.F.; Tan, C.G.; Lin, J.G. Effect of Sn addition on the microstructure and superelasticity in Ti-Nb-Mo-Sn Alloys. J. Mech. Behav. Biomed. Mater. 2012, 13, 156-165. [CrossRef] [PubMed]

12. Zheng, Y.F.; Wang, B.L.; Wang, J.G.; Li, C.; Zhao, L.C. Corrosion behaviour of Ti-Nb-Sn shape memory alloys in different simulated body solutions. Mater. Sci. Eng. A 2006, 438, 891-895. [CrossRef]

13. Xu, W.; Lu, X.; Tian, J.J.; Huang, C.; Chen, M.; Yan, Y.; Wang, L.N.; Qu, X.H.; Wen, C.E. Microstructure, wear resistance, and corrosion performance of Ti35Zr28Nb alloy fabricated by powder metallurgy for orthopedic applications. J. Mater. Sci. Technol. 2020, 41, 191-198. [CrossRef]

14. Carman, A.; Zhang, L.C.; Ivasishin, O.M.; Savvakin, D.G.; Matviychuk, M.V.; Perelom, E.V. Role of alloying elements in microstructure evolution and alloying elements behaviour during sintering of a near- $\beta$ titanium alloy. Mater. Sci. Eng. A 2011, 528, 1686-1693. [CrossRef]

15. Zhao, D.P.; Chang, K.K.; Ebel, T.; Qian, M.; Willumeit, R.; Yan, M.; Pyczak, F. Microstructure and mechanical behavior of metal injection molded Ti-Nb binary alloys as biomedical material. J. Mech. Behav. Biomed. Mater. 2013, 28, 171-182. [CrossRef]

16. Yu, Z.T.; Yu, S.; Cheng, J.; Ma, X.Q. Development and application of novel biomedical titanium alloy materials. Acta Metall. Sin. 2017, 53, 1238-1264.

17. Hashmi, M.L.; Wadood, A. Microstructural, mechanical and shape memory characterizations of Ti-Mo-Sn alloys. Trans. Nonferrous Met. Soc. China 2020, 30, 688-700. [CrossRef]

18. Hamazh, E.; Anuar, Z.Z.; Arudi, I.S.; Ibrahim, M.K.; Bahador, A.; Khaatak, A. Influence of fabrication methods on the microstructures and hardness of Ti-Ni, Ti-Nb and Ti-Ta for biomedical applications. Mater. Today Proc. 2021, 39, 975-978. [CrossRef]

19. Chapala, P.; Kumar, P.S. Effect of alloying elements on the microstructure, coefficient of friction, invitro corrosion and antibacterial nature of selected Ti-Nb alloys. Appl. Surf. Sci. 2019, 469, 617-623. [CrossRef]

20. Nazari, K.; Nouri, A.; Hilditch, T. Mechanical properties and microstructure of powder metallurgy Ti-xNb-yMo alloys for implant materials. Mater. Des. 2015, 88, 1164-1174. [CrossRef]

21. Hsu, H.; Wu, S.; Hsu, S.; Syu, J.; Fo, W. The structure and mechanical properties of as-cast Ti-25Nb-xSn alloys for biomedical applications. Mater. Sci. Eng. A 2013, 568, 1-7. [CrossRef]

22. Wang, B.L.; Zheng, Y.F.; Zhao, L.C. Effects of Sn content on the microstructure, phase constitution and shape memory effect of Ti-Nb-Sn alloys. Mater. Sci. Eng. A 2008, 486, 146-151. [CrossRef]

23. Hao, Y.L.; Li, S.J.; Sun, S.Y.; Yang, R. Effect of Zr and Sn on Young's modulus and superelasticity of Ti-Nb-based alloys. Mater. Sci. Eng. A 2006, 441, 112-118. [CrossRef]

24. Fikeni, L.; Annan, K.; Mutombo, K.; Machaka, R. Effect of $\mathrm{Nb}$ content on the microstructure and mechanical properties of binary Ti-Nb alloys. Mater. Today Proc. 2021, 38, 913-917. [CrossRef]

25. Moraes, P.; Contieri, R.; Lopes, E.; Robin, A.; Caram, R. Effects of Sn addition on the microstructure, mechanical properties and corrosion behavior of Ti-Nb-Sn alloys. Mater. Charact. 2014, 96, 273-281. [CrossRef]

26. Buckley, D.H.; Johnson, R.L. The influence of crystal structure and some properties of hexagonal metals on friction and adhesion. Wear 1968, 11, 405-419. [CrossRef]

27. Chui, P.F.; Jing, R.; Zhang, F.G.; Li, J.H.; Feng, T. Mechanical properties and corrosion behavior of $\beta$-type Ti-Zr-Nb-Mo alloys for biomedical application. J. Alloys Compd. 2020, 842, 155693. [CrossRef]

28. Liu, J.; Chang, L.; Liu, H.R.; Li, Y.H.; Yan, H.L.; Ruan, J.M. Microstructure, mechanical behavior and biocompatibility of powder metallurgy Nb-Ti-Ta alloys as biomedical material. Mater. Sci. Eng. C 2017, 71, 512-519. [CrossRef] 
29. Majumdar, P.; Singh, S.B.; Chakraborty, M. The role of heat treatment on microstructure and mechanical properties of Ti-13Zr-13Nb alloy for biomedical load bearing applications. J. Mech. Behav. Biomed. Mater. 2011, 4, 1131-1144. [CrossRef]

30. Long, M.; Rack, H.J. Review Titanium alloys in total joint replacement-a materials science perspective. Biomaterials 1998, 19, 1621-1639. [CrossRef]

31. Tazari, H.; Siadati, M.H. Synthesis and mechanical properties of aluminum alloy $5083 / \mathrm{SiC}_{\mathrm{np}}$ nanocomposites. J. Alloys Compd. 2017, 729, 960-969. [CrossRef]

32. Xian, X.; Zhong, Z.H.; Zhang, B.W.; Song, K.J.; Chen, C.; Wang, S.; Cheng, J.G.; Wu, Y.C. A high-entropy V35Ti35Fe15Cr10Zr5 alloy with excellent high-temperature strength. Mater. Des. 2017, 121, 229-236. [CrossRef]

33. Xu, L.J.; Chen, Y.Y.; Liu, Z.G.; Kong, F.T. The microstructure and properties of Ti-Mo-Nb alloys for biomedical application. J. Alloys Compd. 2008, 453, 320-324. [CrossRef]

34. Lazurenko, D.; Laptev, L.; Golkovsky, M.; Stark, A.; Paul, J.; Bataev, I.; Ruktuev, A.A.; Song, L.; Gollwitzer, C.; Pyczak, F. Influence of the $\mathrm{Ti} / \mathrm{Al} / \mathrm{Nb}$ ratio on the structure and properties on intermetallic layers obtained on titanium by non-vacuum electron beam cladding. Mater. Charact. 2020, 163, 110246. [CrossRef]

35. Verma, P.K.; Warghane, S.; Nichul, U.; Kumar, P.; Dhole, A.; Hiwarkar, V. Effect of boron addition on microstructure, hardness and wear performance of Ti-6Al-4 V alloy manufactured by laser powder bed fusion additive manufacturing. Mater. Charact. 2021, 172, 110848. [CrossRef]

36. Bertelli, F.; Freitas, E.; Cheung, N.; Arenas, M.A.; Conde, A.; Damborenea, J.D.; Garcia, A. Microstructure, tensile properties and wear resistance correlations on directionally solidified Al-Sn-(Cu; Si) alloys. J. Alloys Compd. 2017, 695, 3621-3631. [CrossRef]

37. Alagića, C.; Cvijovićb, Z.; Mitrovic, S.; Panic, V.; Rakin, M. Wear and corrosion behaviour of Ti-13Nb-13Zr and Ti-6Al-4V alloys in simulated physiological solution. Corros. Sci. 2011, 53, 796-808. [CrossRef]

38. Niinom, M.; Nakai, M.; Hieda, J. Development of new metallic alloys for biomedical applications. Acta Biomater. 2012, 8 , 3888-3903. [CrossRef]

39. Jiang, W.Y.; Wang, J.F.; Zhao, W.K.; Liu, Q.S.; Jiang, D.M.; Guo, S.F. Effect of Sn addition on the mechanical properties and bio-corrosion behavior of cytocompatible Mg-4Zn based alloys. J. Magnes. Alloy. 2019, 7, 15-26. [CrossRef] 